\title{
ENTREVISTA COM SERGIO ROMANELLI
}

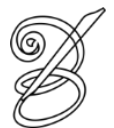 \\ Sátia Marini \\ (Mestranda - POSTRAD/UnB-Brasília/DF/Brasil) \\ smarini@mgnetdf.com.br \\ Patrícia Rodrigues Costa \\ (Mestranda - POSTRAD/UnB-Brasília/DF/Brasil) \\ patriciacosta.tradutora@gmail.com
}

$\mathrm{N}$

ascido em Villa Littorio, sul da Itália, Sergio Romanelli mudou-se para o Brasil em 1998. Na Bahia, morou com tios e primos maternos, onde buscou aperfeiçoar o português adquirido de forma autodidata, pois pretendia ingressar no mestrado. Identificou-se tanto com a língua que a considera sua "colíngua materna" e fala português com uma sutil mistura de sotaques.

Romanelli é professor adjunto na Universidade Federal de Santa Catarina (UFSC) junto ao Departamento de Língua e Literatura Estrangeiras do Centro de Comunicação e Expressão e no Programa de Pós-Graduação em Estudos da Tradução (PGET). É doutor em Linguística Aplicada pela Universidade Federal da Bahia (UFBA), onde também cursou o mestrado, e atua principalmente nos seguintes temas: Língua e Literatura Italiana, Crítica Genética, Linguística Aplicada e Tradução. Além disso, é líder de grupos de pesquisa do CNPq, presidente da Associação Brasileira dos Pesquisadores em Crítica Genética (APCG), membro oficial do Grupo de Trabalho de Crítica Genética da Anpoll, da ABRAPT, editorchefe das revistas In-traduções (PGET) e Manuscrítica (Qualis A2), coordenador do Núcleo de Estudo de Processos Criativos da UFSC (NUPROC), vice-coordenador do Núcleo de Estudos Interdisciplinares de Italiano da UFSC (NEIITA), poeta e tradutor (Virgillito, Alberti, Twain). Em novembro de 2012, esteve presente no III Ciclo de Palestras - "Tradução em Contexto", do Programa de Pós-Graduação em Estudos da Tradução da Universidade de Brasília (POSTRAD/UnB) -, no qual proferiu palestra intitulada "Manuscrito e tradução: espaços de criação". 
Quando de sua visita a Brasília para a palestra acima citada, o senhor falou sobre o trabalho com a Crítica Genética, assunto ainda pouco conhecido no Brasil. Poderia discorrer sobre o processo de estudo em Crítica Genética?

SERGIO ROMANELLI: A CG é uma metodologia relativamente recente, pois surgiu no final da década de 1960, na França, e nos anos 1980, aqui no Brasil, trazida pelo professor Philippe Willemart, da USP. A CG, ao contrário de outras abordagens no âmbito literário, se interessa pela obra como um todo e não somente pela obra editada, que considera somente uma das etapas do processo de criação de determinado autor. Rascunhos, esboços, cadernetas, diários do autor, cartas, livros com marginália, todo aquele conjunto de documentos de processo que atesta o devir da obra interessa aos geneticistas, que, para uma maior legibilidade, o organiza e transcreve, primeiramente, para, em seguida, analisá-lo, fundamentando-se em teorias que deem conta da natureza complexa do objeto de estudo em questão. O geneticista é um arqueólogo da criação que deve procurar essa materialidade espalhada em acervos e bibliotecas públicas e particulares às vezes de difícil acesso e, depois, conforme princípios rigorosos, organizar, transcrever e analisar os documentos.

O senhor disse que, para determinados autores, a obra parece ser sempre provisória. A tradução também tem essa característica, pois são cogitadas muitas opções para os vocábulos e revisões das traduções antes de serem consideradas prontas. Observando as anotações nos manuscritos dos autores e as reflexões dos tradutores, como se aproximam o processo criativo do autor e do tradutor?

SR: A análise de documentos de processo, que a CG possibilita, revela ao pesquisador pelo menos três elementos fundamentais em relação à criação de um texto ou obra: a complexidade desse processo de criação peculiar, sua imprevisibilidade e sua intersubjetividade. Tanto a obra literária de um autor, quanto a tradução ou a pintura de um artista plástico passam por inúmeras fases de construção, revisão, transcrição, decodificação, recodificação, até alcançar uma forma considerada aceitável pelo autor num determinado momento, mas não definitiva. A publicação da obra e da versão da obra naquele exato momento pode ocorrer por vários motivos: cansaço por parte do autor, prazos editoriais, censuras, fatos contingentes ou uma suposta satisfação do autor com sua própria obra, que, logo em seguida ou depois de alguns anos, é por ele mesmo questionada novamente através de revisões, novas edições, acréscimos etc. Por esses motivos, e devido à analise que os documentos possibilitam, podemos afirmar que a obra é sempre provisória, pois nunca alcança um estado acabado ou considerado, tanto pelo autor quanto pelos leitores ou editores. Os manuscritos revelam essa pluralidade negada 
pela obra editada, e as diferentes versões existentes de uma obra, assim como o lento e complexo processo de revisão e construção, a opção por uma versão e não por outra, deixam em aberto outros textos paralelos não revelados ao leitor, mas que são também parte da obra editada e justificam sua precariedade por não ser a única versão existente. Os manuscritos mostram que tanto o processo criativo do autor quanto o do tradutor passam pelas mesmas fases e são norteados por esses três princípios num sistema complexo de criação.

Fale-nos um pouco sobre o seu trabalho com as traduções do imperador Dom Pedro II, sobre o processo que ele utilizava para traduzir $e$ se há marcas de coautoria dos professores/tutores que o acompanhavam nessa tarefa.

SR: O projeto sobre os manuscritos tradutórios do imperador Dom Pedro II começou em 2009 com a pesquisa de mestrado de minha orientanda Rosane de Souza, que dizia respeito às traduções do árabe, especificamente das Mil e uma noites. A partir desse momento, após várias missões de pesquisas, o projeto por mim coordenado e um dos projetos centrais do NUPROC tem nos revelado dados surpreendentes acerca dessa atividade intelectual do imperador. Acessamos, transcrevemos e analisamos manuscritos referentes a traduções de inúmeros idiomas clássicos e modernos: árabe, hebraico, sânscrito, latim, italiano, francês, alemão, espanhol e inglês. Os manuscritos foram encontrados no Arquivo Histórico de Petrópolis e no Instituto Histórico e Geográfico Brasileiro (IHGB). Além dos manuscritos referentes às traduções propriamente ditas de poemas, tragédias, épicos da literatura mundial, conseguimos, também, montar um epistolário consistente e muito importante para traçar essa rede única de relações que o imperador mantinha com intelectuais, políticos e cientistas do mundo todo, a saber: Pasteur, Gobineu, Hugo, Manzoni, Longfellow, Cesare Cantù, etc. Os diários do imperador, um total de 5.500 páginas em que ele anotava muita da sua atividade intelectual e tradutória, também fazem parte do nosso dossiê. Vários graduandos, mestrandos e doutorandos estão desenvolvendo suas pesquisas com esse acervo peculiar e podemos já afirmar que a tradução para Dom Pedro não era somente uma forma de aprender idiomas estrangeiros, mas era um meio estratégico que ele utilizava para entrar em contato com esses intelectuais, para construir sua fama de tradutor e de intelectual e para entrar nesse seleto grupo de iluminados que constituíam a que Pascale Casanova chama de "República mundial das letras". O que nos surpreendeu ao longo desses anos de pesquisa foi, por um lado, o valor desses documentos de processo e, por outro, o desinteresse que até hoje entidades e grupos de 
pesquisa têm mostrado por esse aspecto da vida do imperador. No que diz respeito ao processo criativo do imperador, posso dizer que há recorrências nos manuscritos analisados que levam a supor que ele trabalhasse contemporaneamente em diferentes traduções de vários idiomas de mais obras e que após ter feito a primeira versão de cada texto traduzido a transcrevia ou pedia para que alguém a transcrevesse e retrabalhava nela frequentemente usando na revisão os conselhos dos autores da obra original com quem se correspondia e de intelectuais do seu círculo a quem enviava cópias manuscritas das traduções para que fizessem sua avaliação (é o caso de Manzoni, dos Mota Maia, etc.). No diário ele diz que traduzia do árabe e do sânscrito com Henning ou Seybold, seus professores. Ainda que não apareçam marcas da intervenção deles nos manuscritos, podemos supor que a influência deles na criação do imperador fosse muito grande.

Atualmente, o uso de tradução está sendo reconsiderado como um quinto elemento no ensino de idiomas, associado à leitura, à escrita e à compreensão e fala. Pode-se entender o interesse de D. Pedro II por tradução como uma forma de aprender outros idiomas?

SR: Como falei, sem dúvida, numa fase mais inicial de sua aprendizagem das línguas e da sua educação, a tradução, como era habitual na época, serviu de método para aprender idiomas estrangeiros e suas gramáticas. Mas após esse momento, na maturidade, a tradução alcançou um papel muito mais relevante e complexo: era um meio para constituir uma rede de contatos que lhe serviriam para formar a identidade de seu país e de seu povo do ponto de vista literário e ideológico.

O trabalho de crítica genética é retrospectivo, utiliza documentos rasurados, marcados pelo uso do autor/tradutor, como isso poderá ser recuperado com os autores atuais que muitas vezes escrevem diretamente no computador?

SR: Essa é uma pergunta muito importante, pois frequentemente, ao falar de crítica genética e análise de manuscritos em palestras e em artigos, os leitores e o público em geral questionam a necessidade da CG na era digital. Na verdade, existem softwares, como o Translog, que gravam todo o processo de escrita de um autor se for colocado em seu computador, assim como outras ferramentas utilizadas, por exemplo, pelas editoras para gravar todas as etapas da redação ou revisão de um texto; por isso, felizmente, até na era digital, a análise genética ainda será possível. 
Como o senhor vê o aumento de cursos de tradução no Brasil (graduação e pós-graduação), bem como de revistas acadêmicas que têm como tema principal os Estudos de Tradução?

SR: Vejo isso como um fato altamente positivo. Até dois anos atrás o Programa de PósGraduação em Estudos da Tradução, no qual atuo, o PGET, era o primeiro e único não somente do Brasil, mas da América Latina. Esse programa, fundado por um grupo de docentes da UFSC em 2003, tem sido e continua sendo uma referência para a divulgação dos Estudos da Tradução e a defesa da autonomia dessa disciplina no âmbito acadêmico e científico. Sua ação, nesse sentido, tem se desenvolvido com a promoção de pesquisas, debates, eventos, livros e com a criação de três revistas muito conceituadas, a Cadernos de Tradução, a Scientia Traductionis e a In-traduções. Hoje, assistimos com muita felicidade ao surgimento de outros dois programas em Estudos da Tradução, em Brasília e em São Paulo. Isso evidentemente reforça o percurso feito até aqui e torna os Estudos da Tradução no Brasil mais fortes e visíveis. Ainda há muito caminho a ser percorrido, mas, com certeza, vivemos um momento muito importante para a tradução no Brasil.

O senhor ressaltou em sua palestra que o Brasil tem pesquisas mais adiantadas em Crítica Genética do que a França. Como o senhor percebe esse crescente interesse a respeito da crítica genética e também em relação aos Estudos da Tradução?

SR: Como falei na minha palestra, nas últimas décadas a CG brasileira tem percorrido um percurso epistemológico e teórico próprio, ampliando seu objeto de reflexão para além dos manuscritos literários, tanto que a Associação dos Pesquisadores em Crítica Genética, que antes se chamava APML (Associação dos Pesquisadores do Manuscrito Literário) teve que atualizar seu nome para torná-lo mais condizente com a realidade que estava se formando no Brasil. Hoje, temos a APCG (Associação dos Pesquisadores em Crítica Genética), da qual sou presidente. A partir dos anos 1980, as pesquisas têm se voltado para o estudo de processos criativos nas artes performáticas com o grupo da professora Cecília Salles, na PUC-SP. Outros grupos espalhados pelo país trabalham com tradução e CG e tradução intersemiótica, CG e inclusão social, como é o caso do meu grupo, o NUPROC, em Santa Catarina, e do grupo da professora Sílvia Maria Guerra Anastácio, na Bahia. Outros ainda trabalham com análise de documentos de processo referente a redações de alunos de escolas públicas, com epistolografia, com acervos digitais, etc. O interesse pelo estudo dos processos é algo 
absolutamente contemporâneo do novo paradigma sistêmico descrito por Esteves em seu livro O paradigma do pensamento sistêmico.

O que ainda falta para o Brasil ser reconhecido como importante centro de pesquisa em Estudos da Tradução?

SR: Acho que o que falta é somente uma atitude menos voltada para o exterior, para modelos distantes, tanto teóricos quanto culturais. A época do colonialismo acabou, mas ainda continua existindo uma subserviência intelectual por parte de pesquisadores, docentes e discentes brasileiros que muito me incomoda enquanto estrangeiro. Parte da minha formação acadêmica aconteceu aqui no Brasil, no Nordeste, e aprendi muito. Há profissionais e intelectuais que desenvolvem trabalhos de ponta que nada têm a invejar aos do resto do mundo, tanto nas Humanas quanto nas Exatas. Eu não vejo mais a necessidade de pesquisar no Brasil, por exemplo, autores estrangeiros, quando temos acervos e documentos riquíssimos referentes a personalidades da história e da cultura brasileira que são completamente esquecidos por pesquisadores e instituições, como é o caso de Dom Pedro e seus documentos

136 tradutórios. Nos Estudos da Tradução brasileiros há uma enorme lacuna que é uma pesquisa sistemática sobre a história da tradução no nosso país, e esta me parece ser um objeto de análise urgente e relevante se queremos realmente que nossas pesquisas se tornem internacionais e visíveis. 


\section{REFERÊNCIAS BIBLIOGRÁFICAS SOBRE CRÍTICA GENÉTICA}

BIASI, Pierre-Marc de. A crítica genética. In: BERGEZ, Daniel et al. Métodos críticos para a análise literária. Tradução Olinda Maria Rodrigues Prata. São Paulo: Martins Fontes, 1997.

A genética dos textos. Tradução de Marie-Hélène Paret Passos. Porto Alegre: EdiPUCRS, 2010.

HAY, L. A literatura dos escritores: questões de Crítica Genética. Tradução de Cleonice Paes Barreto Mourão. Revisão técnica de Consuelo Fortes Santiago. Belo Horizonte: Editora UFMG, 2007.

ROMANELLI, Sergio. A gênese de um processo tradutório: os manuscritos de Rina Sara Virgillito. 2006. 534 f. Tese (Doutorado em Letras e Linguística) - Pós-Graduação em Letras e Linguística, Universidade Federal da Bahia, Salvador.

Entre línguas e culturas: as traduções de D. Pedro II. Mutatis Mutandis, v. 4, n. 2. p. 191-204, 2011. Disponível em: <http://aprendeenlinea.udea.edu.co/revistas/index.php/mutatismutandis/article/viewFile/9989/ 9872>. Acesso em: 12 maio 2012.

SALLES, C. A. Crítica genética. São Paulo: Educ, 1992.

SOUZA, Rosane. A gênese de um processo tradutório: As Mil e uma noites de D. Pedro II. 135 f. Dissertação (Mestrado em Estudos da Tradução) - Programa de Pós-Graduação em Estudos da Tradução, UFSC, Florianópolis. 